\title{
MEDIA VIDEO COMPANY PROFILE SEBAGAI SARANA INFORMASI DAN PROMOSI DI PT. SURYA TOTO INDONESIA TbK. KABUPATEN TANGERANG
}

\author{
Erna Astriyani ${ }^{1}$ \\ Andri Lukmana ${ }^{2}$ \\ Agung Irawan ${ }^{3}$ \\ Dosen STMIK Raharja Jurusan Sistem Informasi ${ }^{1}$, STMIK Raharja Jurusan Teknik Informatika ${ }^{2,3}$ \\ Jl. Jendral Sudirman No 40 Modern Cikokol Tangerang ${ }^{1,2,3}$

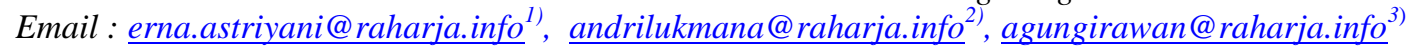

\begin{abstract}
ABSTRAK
Perkembangan teknologi komputer khususnya bidang multimedia, audio visual dan broadcasting sudah sangat berkembang pesat saat ini serta semakin luasnya kebutuhan akan informasi pada masyarakat, maka semakin banyak kontribusi baru dalam menyajikan company profile baik sebagai media informasi maupun sebagai media promosi. PT. Surya Toto Indonesia Tbk. bergerak di bidang manufaktur pembuatan sanitary, berkontribusi untuk menyediakan produk sanitary, merupakan perusahaan yang berpengalaman dalam bidang manufaktur dan menjadi salah satu perusahaan besar di indonesia. PT. Surya Toto Indonesia sekarang ini beroperasi dengan dua pabrik yang bersih dan pabrik pengepasan yang bersih, dan mempekerjakan kira-kira 3,508 orang-orang. Perusahaan dinamis ini melanjut untuk berstandar pada produk yang superior, memasarkan, karyawan bermotivasi tinggi dan perluasan tentang jaringan penjualan yang di seluruh dunia untuk menyediakan produk berkwalitas yang meningkatkan hidup kita.

Dengan tujuan untuk memperkenalkan identitas dan keseluruhan informasi yang terkait didalamnya. $P T$. Surya Toto Indonesia tentunya menginginkan penyajian informasi yang efektif, akurat dan menarik dari segi tampilan maupun isi konten didalamnya. Penyajian informasi yang dikemas dalam bentuk video company profile dirasa sangat berguna untuk tujuan tersebut. Diharapkan video company profile ini bermanfaat dan bisa diimplementasikan oleh PT. Surya Toto Indonesia.
\end{abstract}

Kata Kunci: Kata kunci : Video company profile, teknologi, multimedia, informasi, promosi.

\begin{abstract}
The development of computer technology in particular fields of multimedia, visual and audio broadcasting already very rapidly growing at this time as well as the extent of the need for information on the society, the more recent contributions in presenting company profiles as both a media information and media promotion. PT. Surya Toto Indonesia Tbk. engaged in the manufacture of manufacture of sanitary, contributing to provide sanitary products, is an experienced company in the field of manufacturing and became one of the major companies in indonesia. PT. Surya Toto Indonesia now operates with two clean factory and factory pengepasan clean, and employs approximately 3.508 people. This dynamic company extends to a superior standard of product, market, highly motivated employees and the expansion of the sales network all over the world to provide quality products that improve our lives.

With the aim to introduce the identity and overall information associated therein. PT. Surya Toto Indonesia certainly wants the effective presentation of information, accurate and interesting in terms of the look or content therein. The presentation of the information is packaged in the form of a video company profile is considered particularly useful for that purpose. Expected company profile video is worthwhile and could be implemented by PT Surya Toto Indonesia.
\end{abstract}

Keywords: keywords: Video company profile, technology, multimedia, information, promotion. 


\section{PENDAHULUAN}

Era globalisasi membawa dua dampak, di satu sisi dapat meningkatkan kesempatan di bidang ketenagakerjaan, di sisi lain terhadap dunia usaha kompetisi semakin tajam dan ketat, oleh karena itu dibutuhkan strategi yang tepat dalam mencapai keberhasilan di bidang dunia usaha.

Dalam memasarkan sebuah produk pihak perusahaan membutuhkan program promosi yang memiliki media sarana yang efektif. Dari sarana media yang telah digunakan setiap periode yang telah ditentukan tentunya telah dilakukan evaluasi secara seksama agar program promosi waktu mendatang mempunyai nilai yang lebih baik dibandingkan waktu sebelumnya.

PT. Surya Toto Indonesia didirikan pada Tahun 1978, di tangerang. Pada tahun 1994 PT. Surya Toto Indonesia berhasil memperoleh label dari JIS (Japan International Standard) dan juga berhasil menambah tipe produk yang dihasilkan. Kemudian pada tahun 1999 PT. Surya Toto Indonesia memperoleh sertifikasi ISO 9002.

PT. Surya Toto Indonesia merupakan salah satu produsen produk saniter terbesar di Asia Tenggara. yang berkantor pusat di Tomang Raya, Jakarta Barat. Sejarah perusahaan ini dimulai dari kerjasama antara CV Surya dengan TOTO Ltd di Jepang.

\section{RUMUSAN MASALAH}

PT. Surya Toto Indonesia adalah sebuah perusahaan saniter yang memasarkan sebuah kloset dari dari bahan mentah hingga jadi. Tetapi pada saat ini PT. Surya Toto Indonesia hanya memiliki promosi melalui web atau internet sehingga kurang efektif untuk mempromosikan kepada masyarakat terutama calon customer, saya berencana membuat video compay profile dengan menggunakan sofwear adobe premier yang hasilnya seperti video, video yang saya buat akan menampilkan cara pembuatan dari bahan mentahan menjadi jadi, hasil video tersebut dan akan di uploud melalui youtube, sosial media sehingga pemasaran dari PT. Surya Toto Indonesia lebih meluas lagi.

\section{LANDASAN TEORI}

\section{Pengertian Perancangan}

Menurut Iwan Binanto, (2010:260-261). Perancangan adalah tahap pembuatan spesifikasi mengenai arsitektur program, gaya, tampilan, dan kebutuhan material atau bahan untuk program. Tahap ini biasanya menggunakan storyboard untuk menggambarkan deskripsi tiap scene lain dan bagan alir (flowchart) untuk menggambarkan aliran dari satu scene ke scene lain.

\section{Konsep Dasar Media}

Menurut Maimunah dkk (2012:284) Media adalah sarana untuk menyampaikan pesan atau informasi kepada public dengan menggunakan berbagai unsur komunikasi grafis seperti teks atau gambar atau foto.

Menurut Dewi Immaniar Desrianti (2012:133) "Media adalah segala bentuk yang digunakan untuk menyalurkan informasi.

\section{Konsep Dasar Video Pengertian Video}

Menurut Melvy Ayuningtias, (2011:7). Video merupakan gabungan gambar-gambar mati yang dibaca berurutan dalam suatu waktu dengan kecepatan tertentu. 


\section{Standar dan Format Video}

Menurut Melvy Ayuningtias, (2011:11-13). Standar sistem penyiaran di seluruh dunia terbagi menjadi 3 kelompok diantaranya NTSC (National Television System Comitte), PAL (Phase Alternating Line), SECAM (Sequential Colour Avec Memory)

\section{Konsep Dasar Video Profile}

Menurut Maimunah dkk. dalam jurnal CCIT Vol.5 No.3 2012 : 284 Company Profile adalah sebuah aset suatu lembaga atau perusahaan yang dapat digunakan untuk meningkatkan suatu image atau citra dari perusahaan untuk menjalin kerjasama dengan relasi perusahaan, lembaga dan instansi yang terkait lainnya.

\section{Konsep Dasar Promosi}

Menurut Cipta Halim (2010:45) Promosi adalah media untuk mengenalkan suatu produk barang dan jasa yang baru atau memperkuat brandimage suatu produk yang telah ada sebelumnya.

\section{Bentuk Promosi}

Menurut Kotler dan Armstrong (2010, 440-443).

1. Advertising atau Iklan.

Iklan merupakan salah satu bentuk promosi yang dapat dengan cepat meluas dan meraih target konsumen mereka namun dalam pelaksanaannya, memerlukan dana yang besar.

2. Personal Selling atau Penjualan Personal.

Dikatakan bahwa Personal penjualan Personal merupakan alat paling efektif pada tahap tertentu dalam proses keputusan pembelian, terutama dalam menentukan pembelian, keyakinan dan tindakan yang akan diputuskan.

3. Sales Promotion atau Promosi Penjualan.

Promosi penjualan sering kali tidak terlalu efektif dibandingkan dengan iklan dana penjualan Personal dalam membangun preferensi merek jangka panjang dan hubungan pelanggan.

4. Public Relation atau Hubungan Pelanggan.

Hubungan pelanggan dipercaya dalam hal sponsorship, pembuatan event dan cerita baru dalam perusahaan karena terlihat lebih nyata untuk para konsumen atau pembaca dibanding dengan iklan.

5. Direct Marketing atau Pemasaran Langsung.

Banyak bentuk yang digunakan dalam pemasaran langsung sesuai dengan kebutuhan atau karakteristik setiap perusahaan dan bidang yang digeluti, seperti email langsung, katalog, tele-Marketing, online-Marketing dan sebagainya.

\section{Konsep Dasar Informasi}

Menurut Maimunah, Jurnal CCIT, (2012:284). Informasi adalah data yang telah diolah menjadi sebuah bentuk yang lebih berarti bagi penerimanya, dan bermanfaat dalam mengambil sebuah keputusan.

\section{Jenis-jenis Informasi}

Menurut Rachmat Kriyantono., S.Sos., M.Si, (2011:66-69).

1. Informasi Penyejuk

Informasi keadaan sekarang yang merangkum keadaan umum bisnis atau organisasi.

2. Peringatan 
Berisi penunjuk terhadap sesuatu yang tidak biasa atau barangkali memerlukan tindakan manajerial atau perubahan-perubahan rencana.

3. Indikator Kunci

Berisi ukuran aspek-aspek penting yang berkaitan dengan kinerja organisasi.

4. Informasi Situasional

Informasi terkini tentang proyek, masalah, atau isu penting yang memerlukan perhatian manager.

5. Gosip

Informasi informal yang berasal dari sumber seperti pihak industri yang terkadang berguna untuk menangani suatu masalah.

6. Informasi eksternal

Informasi yang berasal dari luar departemen atau perusahaan. Kadangkala informasi ini masih hangat dan berjangka pendek (misalnya adanya penandatanganan kontrak oleh pesaing), tetap kadangkala berjangka panjang (misalnya studi lingkungan yang dilakukan lima tahun terakhir).

\section{Tahapan Produksi}

\section{Pra Produksi}

Indah Rahmawati (2011:72). Pra produksi adalah sebuah proses produksi yang merupakan tahapan awal dari seluruh kegiatan yang akan datang atau juga disebut sebagai tahapan perencanaan.

\section{Konsep Dasar Multimedia Audio Visual and Broadcasting Pengertian Multimedia}

Menurut Hofstetter (2001) dikutip oleh Hani Dewi Arriesanti dkk dalam jurnal CCIT Vol. 7 No. 2 (2014 : 194), multimedia adalah penggunaan komputer untuk menyajikan dan menggabungkan teks, suara, gambar, animasi dan video dengan alat bantu (tool) dan koneksi (link) sehingga pengguna dapat melakukan navigasi, berinteraksi, berkarya dan berkomunikasi.

\section{Pengertian Audio Visual}

Menutut Atmohoetomo, (2010:4). Audio visual merupakan gabungan dari dua kata yaitu audio yang berarti suara dan visual yang berarti gambar, atau dengan kata lain menjelaskan, "Audio Visual adalah alat peraga yang dapat dilihat dan didengar dalam hal ini gambar yang bergerak menimbulkan suara."

\section{Pengertian Sinopsis}

Menurut Keraf, (2010:12). Sinopsis adalah ringkasan cerita media periklanan atau film, merupakan bentuk atau pendekatan dari sebuah periklanan atau film dengan tetap memperhatikan unsur-unsur pencerminan dari sebuah periklanan atau film tersebut.

\section{Pengertian Storyboard}

Menurut Arifin, (2010:24) Storyboard adalah sebuah teknik shooting management. Disini dibuat daftar pengambilan gambar pada setiap adegan, dan divisualisasikan dalam bentuk sketsa gambar atau storyboard jika diperlukan.

\section{Pengertian Broadcasting}

Menurut Arifin, (2010:16). Broadcasting adalah distribusi audio visual atau video yang mengirimkan sinyal program untuk penonton. 


\section{PROGRAM APLIKASI PENUNJANG VIDEO PROFILE}

Adobe Prmiere CS6

Menurut Melvy Ayuningtyas (2011 : 23) Adobe Premiere merupakan program untuk menyunting dan mendesain film dan video, disamping juga dapat digunakan untuk membuat desain iklan.

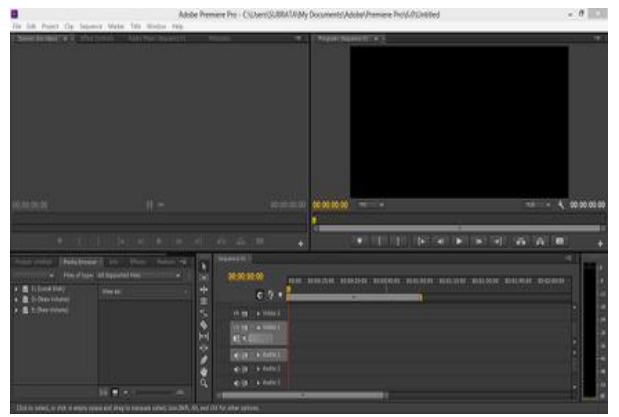

Gambar 1. Adobe premier CS6

Adobe After Effect

Menurut Hendi Hendratman (2010 : 23) Adobe After Effect merupakan software motion graphics yang dapat digunakan sebagai software compositing, animasi dan video effect.

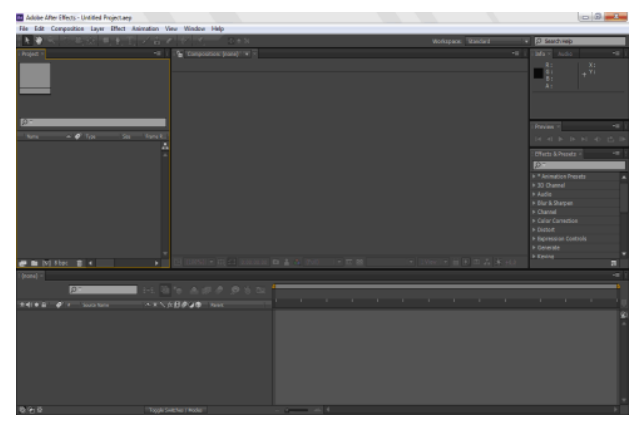

Gambar 2. Adobe After Effect

\section{Adobe Photoshop CS3}

Menurut Lusyani Sunarya, Diktat Perkuliahan Aplikasi Program Komputer Mavib II pada pertemuan 8 (2013 : 49) Adobe Photoshop merupakan sebuah program yang mempunyai banyak fasilitas dan kemampuan untuk mengolah dan memanipulasi tampilan image, Adobe Photoshop sangat membantu Anda di dalam memoles hasil photografi.

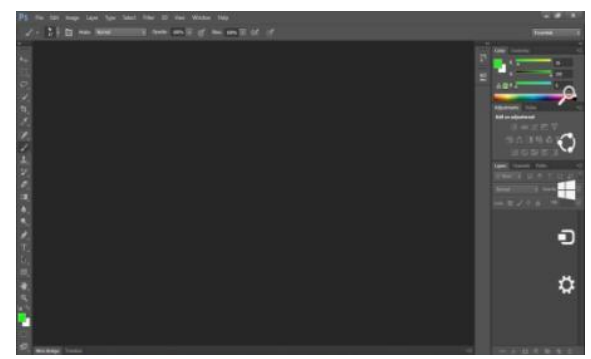

Gambar 3. Adobe Photoshop CS6

\section{LITERATURE REVIEW}

1. Perancangan Company Profile Berbasis Profile Berbasis Video Sebagai Media Promosi SMK Muhammadiah 1 Kepanjen, 2010, Malang, adalah salah satu judul Skripsi yang di buat oleh Fariz Setia Kusuma, selaku mahasiwi Universitas Negeri 
Malang. Penelitian ini menjelasan tentang Pembuatan video profile sebagai media promosi SMK Muhammadiyah 1 Kepanjen.

2. Perancangan Video Company Profile Agrowisata Sondokoro Tasikmadu Karanganyar 2011, adalah salah satu judul Skripsi yang dibuat oleh Ratih Erlin Andriana Lupitasari selaku mahasiswa Universitas Nasional Informatika dan Komputer FTI UNSA. Penelitian ini menjelaskan tentang pembuatan video company profile pariwisata yang berada di karanganyar.

3. Perancangan Aplikasi Multimedia Interaktif Company Profile Generic, 2011, Garut adalah salah satu judul Jurnal yang dibuat oleh Septiana Firdaus, Dhami Johar Damiri, Dewi Tresnawati selaku mahasiswa Sekolah Tinggi Teknologi Garut. Penelitian ini menjelaskan tentang pembuatan aplikasi interaktif company profile generic.

4. Perancangan Company Profile Efrat Production Malang, 2010, Malang, adalah salah satu judul Jurnal yang dibuat oleh Ramdhani Dwi Cahya Adi, Selaku mahasiswa Universitas Negeri Malang. Penelitian ini menjelaskan tentang pembuatan video company profile Efrat production malang.

5. Perancangan Video Company Profile Sebagai Media Promosi dan Informasi di SMA Institut Indonesia Semarang 2014, Semarang, adalah salah satu judul Jurnal yang dibuat oleh Ratih Devi Indriani selaku mahasiswa Sekolah Tinggi Teknologi. Penelitian ini menjelaskan tentang pembuatan video company profile sebagai media promosi dan informasi di sma institut indonesia semarang.

\section{METODE PENELITIAN}

Agar perolehan data lebih akurat dipenelitian ini, terdapat beberapa penerapan metode, yaitu : (1). Metode Analisa Permasalahan. Metode ini merupakan suatu metode yang digunakan untuk menentukan topik permasalahan penelitian, dalam hal ini dilakukan dengan bentuk interview yang menanyakan tentang permasalahan - permasalahan yang terdapat pada lembaga instansi yang terkait dengan proses mempromosikan sekolah; (2). Metode Pengumpulan Data yaitu cara untuk mendapatkan data dengan jalan pengamatan secara langsung ke lokasi (Observasi), Interview ataupun dari kajian pustaka; (3).Analisa Data berupa pengolahan data atau informasi yang diangkat dari hasil perancangan dan penelitian terhadap video company profile PT. Surya Toto Indonesia Tangerang yang akan dianalisa dan diolah menggunakan software atau aplikasi program yang mendukung dalam proses perancangan; (4).Metode Analisa Perancangan, dalam produksi Perancangan Video company Profile Sebagai Media Promosi pada PT. Surya Toto Indonesia tangerang dipergunakan aplikasi- aplikasi penunjang diantaranya aplikasi adobe premier cs6 sebagai pengolah video setelah dilakukan produksi, sedangkan aplikasi Adobe After Effects CS 5dipergunakan untuk pembuatan animasi bumper saat opening maupun closing; (5). Konsep Dasar Media berisi mengenai Preproduction, Production, dan Postproduction.

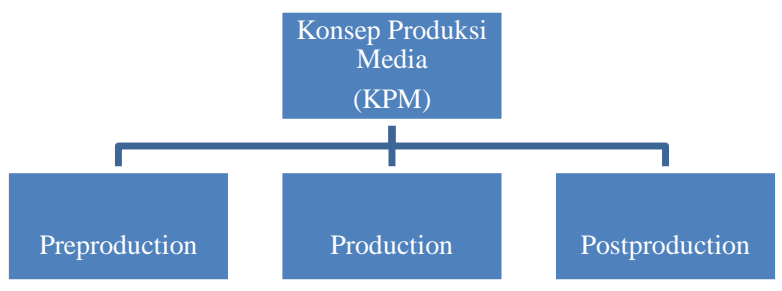

Gambar 4. KPM 


\section{Preproduction}

Untuk Preproduction adalah step atau langkah dimana dimulainya ide, perencanaan dan persiapan dari Konsep Produksi MAVIB. Ada tujuh langkah Preproduction dalam Konsep Produksi MAVIB, dimulai dari Ide yang dituangkan secara sistematis, lalu diikuti dengan pembuatan sinopsis, Script Writting dan Storyboard.

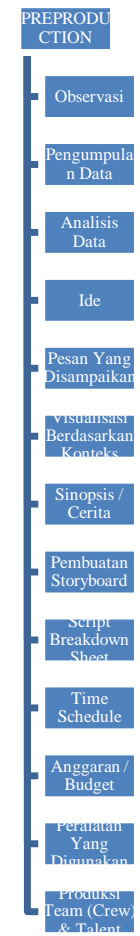

Gambar 5. Preproduction

\section{Storyboard}

Storyboard adalah rancangan berupa sket gambar yang dilengkapi dengan petunjuk atau catatan pengambilan gambar untuk kebutuhan shooting. Selama proses pra produksi, perencanaan yang berhubungan dengan visualiasasi yang akan dibuat membutuhkan Storyboard sebagai media bantuannya.

\section{Scene 1}

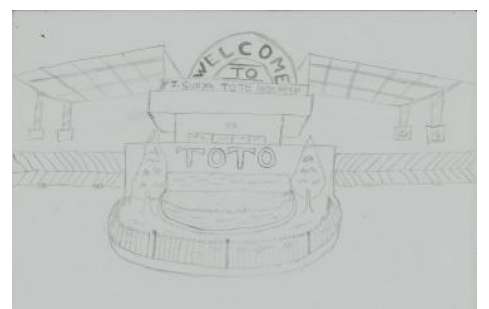

Gambar 6. Bumper Opening video gedung PT. Surya Toto Indonesia

Ext/Gerbang Perusahaan/Siang/Full Shot

Menggambarkan situasi, video gerbang utama PT. Surya Toto Indonesia yang luas. 
Scene 2

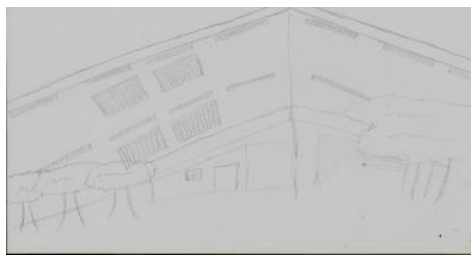

Gambar 7. Menampilkan video gedung PT. Surya Toto Indonesia

Ext/Gedung Perusahaan/Siang/Full Shoot

Menggambarkan gedung PT. Surya Toto Indonesia.

Scene 3

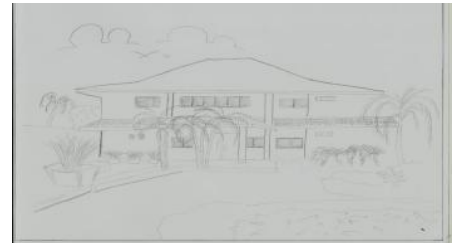

Gambar 8. Menampilkan video tampak depan gedung kantor PT. Surya Toto Indonesia

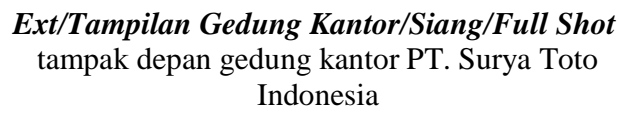

Scene 4

gambar 9. Menampilkan video ruang meeting PT.Surya Toto Indonesia

Ext/Ruang Meeting Perusahaan/Siang/Full Shot

Menampilkan situasi ruang meeting PT. Surya toto Indonesia

Scene 5

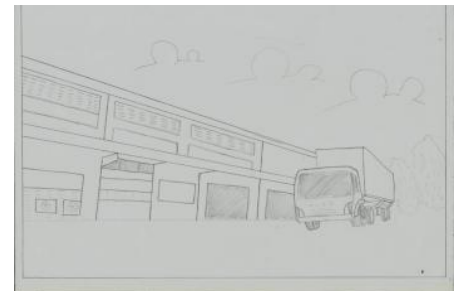

Gambar 10. Menampilkan video Warehouse PT.Surya Toto Indonesia

Ext/Warehouse/Siang/Medium Shot Menggambarkan video Warehouse PT.Surya Toto Indonesia 
Scene 6

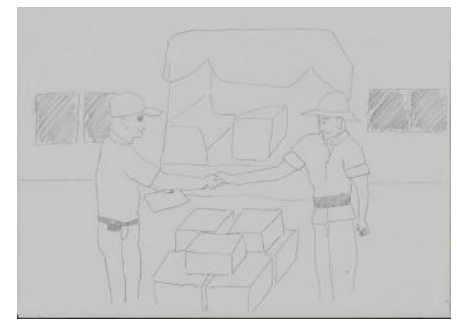

Gambar 11. Menampilkan video salah satu karyawan yang melakukan bakti sosial.

Ext/Bakti Sosial/Siang/Knee Shot

Menggambarkan video karyawan PT. Surya

Toto Indonesia yang melakukan bakti sosial.

Scene 7

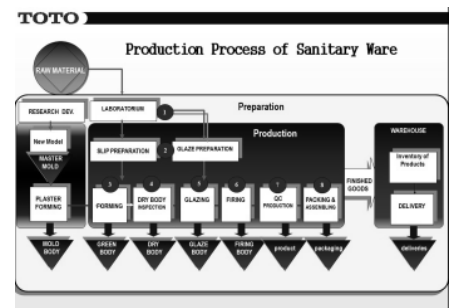

Gambar 12. Proses Produksi

Proses Produksi

Menggambarkan cara pembuatan proses produksi

Scene 8

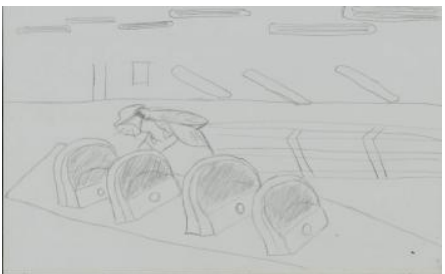

Gambar 13. Menampilkan video forming

Int/Ruang Forming/Siang/Medium Shot

Menggambarkan video forming dari PT.Surya Toto Indonesia

Scene 9

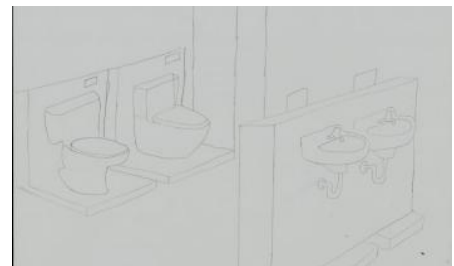

Gambar 14. Menampilkan Show Room

Int/Siang /Show Room Perusahaan/Full Shot Menggambarkan Show Room hasil dari produksi PT.Surya Toto Indonesia 


\section{Setting Alat}

Dalam pembuatan video profile menggunakan alat Camera, Tripod, dan Microphone. Untuk Camera yang digunakan penulis menggunakan Camera panasonic MD10000. Dalam Video audio visual ini banyak digunakan dilokasi dalam kantor. Sedangkan pengambilan suara untuk wawancara menggunakan Mic Pro Kenwood KW-321

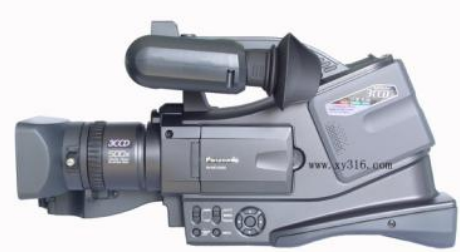

Gambar 15. Kamera MD 10000 Panasonic

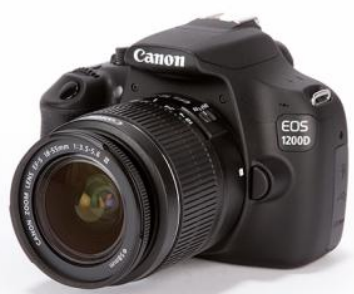

Gambar 16. Kamera Canon 1200D

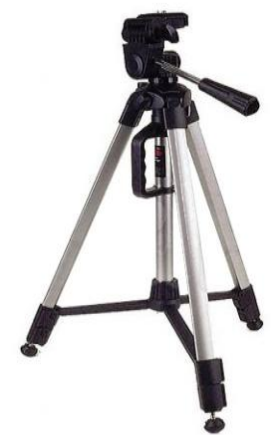

Gambar 17. Tripod kamera

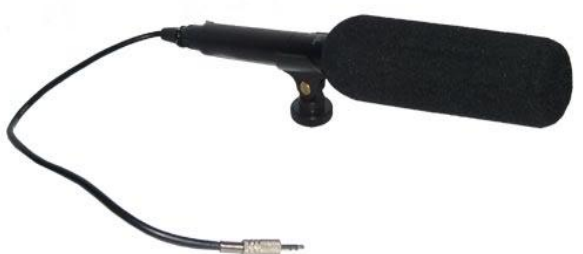

Gambar 18. microfon Shotgun

\section{Production}

Production adalah proses pengambilan gambar atau shooting video dengan bekerjasamanya antara pemain dan crew untuk pewujudan rumusan dari tahap preproduction dalam bentuk skenario, naskah, dan storyboard yang telah dibuat. 


\section{Strategi Multimedia}

Geografi : • Khusus: Wilayah Tangerang

- Umum : Wilayah Indonesia

Demografi : $\quad$ Jenis Kelamin : Pria \& Wanita

- Usia : $20 \mathrm{~s} / \mathrm{d} 35$ tahun

- Kelas Ekonomi : Menengah

- Sasaran $\quad$ : Calon Customer dan Mitra PT. Surya Toto Indonesia

Psikografi : Calon Customer dan Mitra Perusahaan yang ingin lebih mengetahui secara lebih jelas mengenai PT. Surya Toto Indonesia.

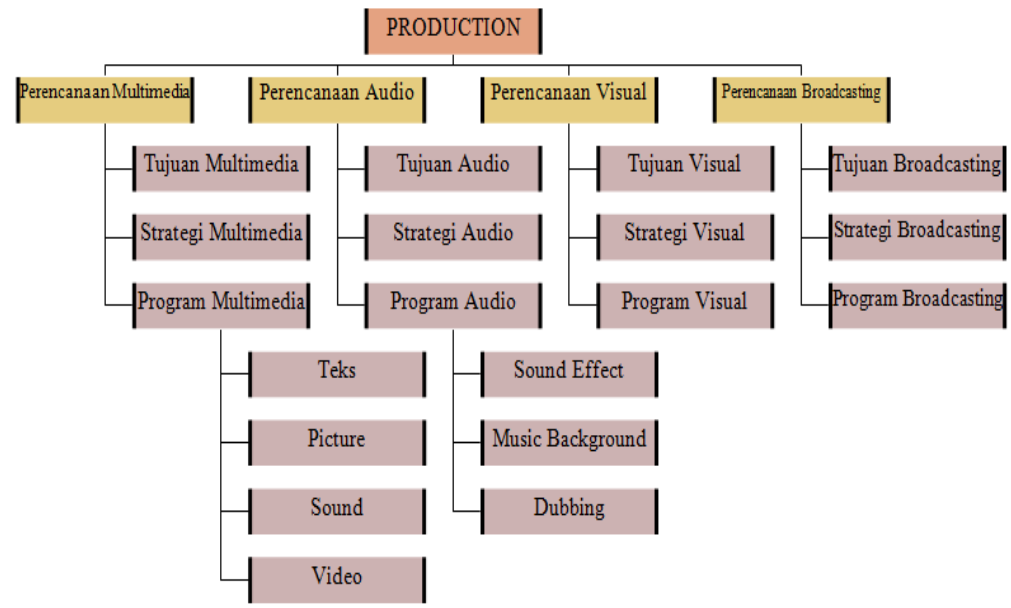

Gambar 19. Production

\section{Postproduction}

Tahap postproduction adalah proses finishing sebuah karya sampai menjadi sebuah video yang utuh dan mampu menyampaikan sebuah cerita atau pesan kepada audience. Dalam proses postproduction semua gambar yang didapat pada proses production di satukan dan di edit oleh seorang editor.

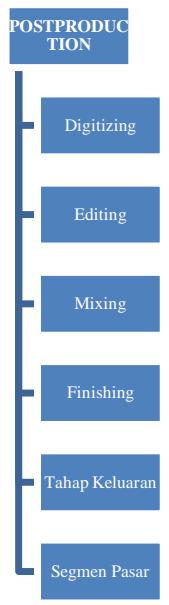

Gambar 20. Postproduction

\section{KESIMPULAN}

Setelah penulis melakukan penelitian pada PT. Surya Toto Indonesia, penulis berkesimpulan bahwa Media video company profile perusahaan yang dikemas dalam bentuk video company profile sangat di perlukan bagi PT. Surya Toto Indonesia 
khususnya di bidang saniter dan dengan adanya Media video company profile perusahaan tersebut dapat meningkatkan suatu image atau citra dari masyarakat agar tertarik dengan produk dari PT. Surya Toto Indonesia.

Dalam pembuatan media video company profile yang baik, harus memperhatikan faktor-faktor yang berhubungan dengan PT. Surya Toto Indonesia yang bersangkutan. Dalam hal ini penulis menyesuaikan dengan keinginan stakeholder, mulai dari pembuatan pengambilan gambar, tampilan video, isi pesan dan penutup. Hal ini bertujuan untuk memperkuat media video company profile dalam mempromosikan Produk saniter dan mengajak masyarakat untuk dapat berlangganan dan menjadi pelanggan tetap dari PT. Surya Toto Indonesia.

\section{DAFTAR PUSTAKA}

[1] Arifin, Eva. 2010. “Broadcasting To Be Broadcaster”. Graha Ilmu. Yogyakarta.

[2] Arriesanti, Hani Dewi, Muhamad Yusup, Ceria Marcelia. Penerapan Multimedia Audio Galery Ilearning Community And Services (Magics) Sebagai Media Penyimpanan Dokumentasi Pada Perguruan Tinggi Raharja. Journal CCIT Vol. 7 No. 2 - Januari 2014. Perguruan Tinggi Raharja. Tangerang.

[3] Atmohoetomo. 2010. "Media Audio Visual Pendidikan dan Proses Produksi Programnya”. Pusdiklat Perpustakaan IKIP. Yogyakarta.

[4] Ayuningtyas, Melvy. 2011. "Ngedit Video Dengan Adobe Premiere CS3", Dunia Komputer. Yogyakarta.

[5] Binanto, Iwan. 2010. Multimedia Digital (Dasar Teori dan Pengembangannya). ANDI. Yogyakarta.

[6] Halim, Cipta. 2010. "Tips Praktis Promosi Online Untuk Berbagai Event". Gramedia. Jakarta.

[7] Hendratman Hendi, ST. 2010. "The Magic of Adobe After Effects", Informatika, Bandung.

[8] Immaniar, Dewi, Sudaryono dan Dwi Ayu Ningrum. 2012. "Enriching Company Profile Sebagai Penunjang Media Informasi Dan Promosi Pada Perguruan Tinggi Raharja", Jurnal CCIT (Vol.7 No.3). Tangerang.

[9] Kotler dan Armstrong.2010, Principles of Marketing (Edisi 13). Pearson. United States of America.

[10] Maimunah, Lusyani Sunarya dan Nina Larasati. 2012. "Media Company Profile Sebagai Sarana Penunjang Informasi Dan Promosi", Jurnal CCIT (Vol.5 No.3). Tangerang.

[11] Sunarya, Lusyani. 2013. Diktat Mata Kuliah Diktat Mata Kuliah Aplikasi Program Komputer MAVIB II. Perguruan Tinggi Raharja. Tangerang. 